\title{
THE EFFECT OF A READING COMPREHENSION SOFTWARE PROGRAM ON STUDENT ACHIEVEMENT IN MATHEMATICS
}

Dr. David E. Proudfoot, University of Phoenix, Arizona USA

E-mail: dproudfoot@email.phoenix.edu

ART I C LE IN F O

Original Article

Received: May, 19.2016.

Revised: June, 06.2016.

Accepted: June, 08.2016.

doi:10.5937/IJCRSEE1601039P

UDK

$159.922 .72 .072-057.875$

$159.953 .5-057.875$

\section{Keywords:}

reading comprehension,

mathematics,

computer based instruction,

problem solving,

critical thinking,

language.

\begin{abstract}
A B S T R A C T
In an effort to increase student achievement, research was conducted to determine the degree in which a reading comprehension software program effected the reading and math abilities of fourth and fifth grade students. Cognitive and educational studies were examined to select a reading comprehension software program as an intervention that would produce positive results in reading comprehension and possibly transfer positive results to achievement in other academic areas, specifically in math. The effects of the intervention were measured by assigning subjects to an experimental group. The total sample consisted of 39 students who were deficient in reading comprehension, and also exposed a significant weakness with word problem items on mathematical assessments. Four instruments were used to collect data before and after the treatment to measure student achievement. To determine the degree to which the software program effected student achievement, data from the four instruments were analyzed using SPSS software. A paired-samples dependent $t$ test and a Pearson Product Moment Correlation Coefficient was computed with ratio level data to test for a correlation between increased math scores and reading comprehension scores. Results yielded statistically significant and positive results in increasing reading comprehension skills that could possibly benefit students in reading and understanding mathematical problems. Results did not conclusively support that the increase of reading-comprehension skills had a collateral effect on students scoring higher with math word problems. The results are conducive to providing insight to educational leaders who plan to implement software as a means for increasing student achievement.
\end{abstract}

(C) 2016 IJCRSEE. All rights reserved.

\section{INTRODUCTION}

The ability to read proficiently is a fundamental skill that affects the learning experiences and school performance of children and adolescents. Students who are competent readers, as measured by their performance on reading tests, are more likely to perform well in other subjects, such as math and science (Hyde, 2007; Carnine and Carnine, 2004). State assessments in Florida have been de-

\section{Corresponding Author}

Dr. David E. Proudfoot, University of Phoenix, Arizona USA, E-mail: dproudfoot@email.phoenix.edu

\section{(i)}

This work is licensed under a Creative Commons Attribution 4.0 International license. The article is published with Open Access at www.ijcrsee.com signed to measure student achievement and have been aligned with the Common Corebased standards of Florida that serve as the instructional benchmarks for instruction in the Florida schools. The test specifications for the suite of assessments assume that students are able to read, understand, and then explain their thinking in a reasonable format. For that reason, difficulty with reading comprehension could have a negative impact on math scores. An interesting trend occurred at one Central Florida elementary school, whereby students who were deficient in reading comprehension also demonstrated a weakness with performance-task, word problem items on the state mathematical assessment. This problem, which impacts student achievement and affects state accountability measures, created an investigative opportunity to conduct research that sought to test whether a reading compre- 
hension software intervention could result in progress in reading comprehension and could transfer to achievement in mathematics.

Cognitive and educational studies that address elements of reading comprehension, connections to mathematical achievement, and software design characteristics that seem to make a difference in student achievement are used in the selection of an intervention. There are several reading comprehension skills that if absent would greatly affect math word problem achievement (Crowe, 2005; Pany and McCoy, 1988; Shany and Biemiller, 1995; and Fuentes, 1998). Adams (2003) revealed that the ability to decode and comprehend text is required to complete the initial phases of the four-step problem-solving process of Polya (1945). The third phase relies on the ability of the student to select and use appropriate strategies to respond to the problem. In order to select and use an appropriate strategy, students need the reading comprehension skill of making connections of the solution strategy to schema (Jitendra, DiPipi, and Perron-Jones, 2002). Research confirms the schema-based strategy as an effective strategy for increasing the number of correctly solved multiplication and division word problems. A student has a greater chance of depicting the patterns of relationships as well as their linkages to mathematical operations by using the schema-based strategy.

Research uncovers that instruction that models the strategy of thinking out loud and the analysis and solution process for sample word problems is helpful with improving the comprehension of text for students (Graesser, Singer, and Trabasso, 1994; Steele and Steele, 1999). Furthermore, there have been significant relationships between mathematics scores and reading scores, which suggest that the number of comprehension questions answered and story propositions recalled correctly can have a direct affect on math achievement. Therefore, comprehension of text which can have a direct effect on math achievement can be improved by using the instructional strategy of modeling.

Cognitive development theories of $\mathrm{Vy}$ gotsky (1978) offer support when discussing the effects that the instructional strategy of modeling can offer. In terms of social influences on cognitive development, Vygotsky places emphasis on children discovering and developing new understandings through social interaction with a skillful tutor. The tutor may model behaviors and/or provide verbal instructions for the child. Vygotsky refers to this as cooperative or collaborative dialogue.
The child seeks to understand the actions or instructions provided by the tutor then internalizes the information, using it to guide or regulate their own performance. According to Vygotsky, this type of social interaction involving cooperative or collaborative dialogue promotes cognitive development.

Cooperative dialogue through social interactions allows for children to develop language which can become a powerful tool of intellectual adaptation. Vygotsky (1987) considered private speech as the transition point between social and inner speech, the moment in development where language and thought unite to constitute verbal thinking. Vygotsky viewed private speech as a means for children to plan activities and strategies and therefore aid their development. Language is therefore an accelerator to thinking and understanding. Vygotsky noted that private speech does not merely accompany a child's activity but acts as a tool used by the developing child to facilitate cognitive processes, such as overcoming task obstacles, enhancing imagination, thinking, and conscious awareness. Children use private speech most often during intermediate difficulty tasks because they are attempting to self-regulate by verbally planning and organizing their thoughts (Winsler et al., 2007). The frequency and content of private speech are then correlated with behavior or performance. For example, private speech appears to be functionally related to cognitive performance and appears at times of difficulty with tasks related to executive function, problem solving, and mathematics.

Cognitive and educational studies provide encouragement for any experiment that attempts to improve student achievement by utilizing a reading program that promotes specific strategies in decoding and comprehension through teacher think-aloud and explicit instruction. Educational technology has demonstrated a significant positive effect on student achievement. Kulik (1994) conducted a meta-analysis of 254 controlled studies of students from kindergarten through higher education, which found that computer-based instruction (CBI) had an average effect size of 0.30 . For individual studies in which differences in achievement were statistically significant, the difference favored CBI in 94 percent of the cases. Specifically, the studies reveal that the use of technology helps students gain skills in reading comprehension. 


\section{MATERIALS AND METHODS}

Research was conducted with fourth and fifth grade students at an elementary school in Central Florida. The object of the research was testing the degree in which a reading comprehension software program positively effected student learning in mathematics and raise student achievement. The treatment covered 39 students ( 25 boys and 11 girls). Watson (2001) stated extremely heterogeneous populations required large sample sizes. The participants for this study were not extremely heterogeneous. Participants in this study had three attributes in common: a student enrolled in the fourth or fifth grade at the elementary school, a student who was deficient in reading comprehension skills, and a student who exposed a significant weakness with performance-task, word problem items on mathematical assessments. Although there may have been other attributes that varied for participants, for the purposes of this study that supported the research questions, participants were sufficiently homogeneous to justify a smaller sample size. The ethnic background of the sample was as follows: $24 \%$ (9 out of 39) Caucasian, $43 \%$ (17 out of 39) African American, and 33\% (13 out of 39) Hispanic.

This research was guided by the following research questions:

1. What are the effects of the reading comprehension software intervention on the reading ability of students?

2. Will increased performance with reading comprehension have a collateral effect on students scoring higher with math word problems?

3 . Is it possible for reading comprehension skills to be transferred to other academic areas, specifically in mathematics?

The interest through research focused on testing whether a reading comprehension software intervention could result in progress in reading comprehension, and likely transfer to achievement in mathematics. The subjects were assigned to the experimental group so that all 39 students would have an opportunity to improve. The general population of fourth and fifth grade students were assigned to the control group. The treatment allowed for students to receive practice in using basic reading improvement strategies. They worked with interactive exercises to determine main idea, make inferences, and draw conclusions. It ap- peared that instruction in higher-order thinking skills (determining main idea, making inferences, and drawing conclusions) were common threads for improving the comprehension of text that could lead to the problem-solving skill (e.g., information research, comparing and contrasting, synthesizing, analyzing, and evaluating) development that was necessary to solve word problems.

The intervention for this research aimed to improve reading comprehension by targeting language structures and modeling. The computer-based instructional program selected for this study cultivated progress in critical thinking and reading comprehension skills that would likely transfer to other academic areas. The literature revealed that there were specific software design characteristics that seemed to make a difference in the amount and quality of student learning. Several studies (Bialo and Sivin-Kachala, 1996; Sasser, 1991) demonstrated the importance of (a) having learners exercise some level of control over the pace and sequence of their instruction, (b) guiding students towards making correct answers rather than simply requiring them to persist until they respond correctly, (c) including embedded cognitive strategies, and (d) having the skills or concepts to be learned involve motion or action. The computer-based instructional program selected for this study satisfied four out of these four design characteristics found in the research that seemed to make a difference in the amount and quality of student learning.

The reading comprehension software program used in this study was designed for students in grades three through five. The program contained 120 passages and 1,320 questions. The program contained a feature that provided immediate feedback for students throughout the duration of the program. Assessments placed students in appropriate units of instruction and students advanced as they demonstrated readiness. The student's understanding of each of three texts was measured with reading comprehension questions related to main idea, sequence, inference, and interpretation.

As part of the regular curriculum, all students received reading-comprehension instruction. The teacher used the reading instructional curriculum that had been adopted by the district, which consisted of reading textbooks, related materials, and charts provided by the publishing company. All students participated in a daily 90 -minute language arts block, which consisted of 25 to 60 minutes of 
whole-group instruction and 45 to 60 minutes of small-group instruction. The whole-group instruction included phonemic awareness, phonics and fluency, and vocabulary and comprehension. The regular reading curriculum also contained a 30-minute block where students participated in a DEAR program. The study used this block of time to implement the intervention.

Thirty-nine students in the experimental group were exposed to the intervention in a computer lab setting for five weeks. Each participant had access to their own computer, headphones, and the computer software program during a 30-minute daily block of time. At the conclusion of the study, students in the experimental group were exposed to the intervention for a maximum of 12.5 hours or 750 minutes depending on their attendance record. The experimental group consisted of fourth and fifth grade students. Despite the difference in ages, all students in the experimental group received the intervention in the same setting. The control group remained with the regular education teacher during a 30-minute block of time. During this time, the student participated in activities that consisted of independent silent sustained reading or group read-aloud reading by the teacher or another student.

The study used four instruments to collect data to measure student achievement: These instruments consisted of (a) embedded pre- and posttest scores in the reading comprehension software program, (b) pre- and posttest scores on the Standardized Test for the Assessment of Reading (STAR), (c) student performance in the classroom setting as measured by a Mastery Skills Checklist for Reading and Literature, and (d) reliable pre-and posttests in which test items and content were closely matched to summative state assessments that assesses the curriculum standards in reading and in mathematics. The Teacher Program Manager (TPM) is the centralized student record-keeping and management system in the reading comprehension software program and is designed to track student performance during the course of the treatment. The primary measurement instrument in this study utilized pre- and posttest results that were embedded in the software program of the reading comprehension intervention. In order to get a fuller picture of the effects of the treatment on student achievement, pre and post test scores on the Standardized Test for the Assessment of Reading (STAR) were used to test the effect of the independent variable of a reading comprehension intervention on student achievement. Achievement changes on reading pre- and posttests were triangulated with student performance in the classroom setting. The progress of each student was measured by his or her teacher and was based upon the classroom work of the student, observations, and tests. Progress was tracked and monitored on a district-created Mastery Skills Checklist which consisted of a list of standards in reading/language arts that a student needed to master based on state standards. A skill was considered mastered if the student had demonstrated a $70 \%$ success rate on the assessment. The number of reading/language arts skills mastered by each student at the beginning and at the end of this study was collected to determine student performance. The ten reading/ language arts skills indicated on the Mastery Skills Checklist were:

1. the student uses simple strategies to determine meaning and increase vocabulary for reading, including the use of prefixes, suffixes, root words, multiple meanings, antonyms, synonyms, and word relationships;

2. the student reads text and determines the main idea or essential message, identifies relevant supporting details and facts, and arranges events in chronological order;

3 . the student identifies author's purpose in simple text;

4. the student reads and organizes information for a variety of purposes including making a report, conducting interviews, taking a test, and performing an authentic task;

5. the student recognizes when the text is primarily intended to persuade;

6. the student recognizes the use of comparison and contrast in a text;

7. the student selects and uses a variety of appropriate reference materials, including multiple representations of information, such as maps, charts, and photographs to gather information for research projects;

8. the student understands the develop and plot and how conflicts are resolved in a story;

9. the student recognizes cause and effect relationships in literary texts;

10. the student knows the similarities and differences among the characters presented in various texts.

Pre-and posttest scores from a summative mathematic assessment were used to explore whether or not increased performance 
with reading comprehension had a collateral effect on students scoring higher with math word problems.

Data from the four instruments were analyzed with SPSS using a paired-samples dependent $t$ test. Also, a Pearson Product Moment Correlation Coefficient was computed with ratio level data to test for a correlation between increased math scores and reading comprehension scores.

\section{RESULTS}

There were 39 students selected to participate in the study, but only 35 produced viable data. Three students selected to participate in the study did not attend the summer school session of the school year, in which the five week duration of the study took place and one student did not gain parental permission to participate in the study. The results are presented by the three research questions that were used to guide the study.

Research Question 1: What are the effects of the reading comprehension software intervention on the reading ability of students?

To determine the effect of the reading comprehension software program on student achievement, a paired-samples $t$-test at a $95 \%$ confidence interval was conducted to determine the statistical significance between the pre- and posttest scores on reading comprehension assessments that were embedded in the software program. Posttest scale scores of students averaged 9.62 percentage points higher than pretest scores after treatment. The test produced a two-tailed significant coefficient of .000 which proved that the effect of the reading comprehension software program was statistically significant in testing whether a reading comprehension software intervention could result in progress in reading comprehension.

To further determine the effect of the reading comprehension software program on student achievement, a paired-samples $t$-test at a $95 \%$ confidence interval was conducted to determine the statistical significance between the pre- and posttest scores of students on the STAR Assessment. In order to provide a basis for deriving the norm-referenced scores, on the STAR assessment, it was necessary to convert all the results of STAR Reading tests to scores on a common scale. STAR Reading software does this in two steps. First, maximum likelihood was used to estimate each student's location on the Rasch model, which provides a foundation for the measurement of quantitative attributes and traits on a continuum. Second, the Rasch ability scores were converted to STAR Reading Scaled Scores. STAR Reading Scaled Scores range from 0 to 1400. Posttest scale scores of students averaged 108 scale score points higher per student after treatment. The test produced a two-tailed significant coefficient of .000 which proved that the effect of the reading comprehension software program was statistically significant in testing whether a reading comprehension software intervention could result in progress in reading comprehension.

To further determine the effect of the reading comprehension software program on student achievement, data that supported achievement gains on the reading pre- and posttest was triangulated with student performance in the classroom setting as indicated by the Mastery Skills Checklist. to further determine the effect of the reading comprehension software program on student achievement. Ten reading skills, to measure student progress in reading, were assessed before and after the intervention. The progress of each student was measured by his or her teacher and was based upon the classroom work of the student, observations, and tests. Pre-intervention and post-intervention data recorded by the teacher on a checklist was analyzed by the researcher using SPSS software.

Table 1 reveals that the percentage of students who experienced an increase in the number of reading skills increased after the treatment.

Table 1. The percentage of students who mastered each Mastery Skill in Reading before and after treatment

\begin{tabular}{|c|c|c|c|}
\hline \multirow[b]{2}{*}{ Mastery Skill } & \multicolumn{2}{|c|}{$\frac{\text { Percentage }}{\text { Mastered }}$} & \multirow{2}{*}{$\begin{array}{l}\text { Per- } \\
\text { centage } \\
\text { gained } \\
t\end{array}$} \\
\hline & $\begin{array}{l}\text { Before } \\
\text { treatmenttr }\end{array}$ & $\begin{array}{l}\text { After } \\
\text { eatment }\end{array}$ & \\
\hline 1. Uses simple strategies & 16.7 & 66.7 & 50 \\
\hline $\begin{array}{l}\text { 2. Determines the main } \\
\text { idea }\end{array}$ & 16.7 & 75 & 58.3 \\
\hline $\begin{array}{l}\text { 3. Determines author's } \\
\text { purpose }\end{array}$ & 61.1 & 66.7 & 5.6 \\
\hline $\begin{array}{l}\text { 4. Reads and organizes } \\
\text { information }\end{array}$ & 38.9 & 47.2 & 8.3 \\
\hline $\begin{array}{l}\text { 5. Recognizes persuasive } \\
\text { text }\end{array}$ & 36.1 & 50 & 13.9 \\
\hline 6. Makes comparisons & 22.2 & 30.6 & 8.4 \\
\hline $\begin{array}{l}\text { 7. Uses reference materi- } \\
\text { als }\end{array}$ & 69.4 & 74.9 & 5.5 \\
\hline 8. Understands plot & 41.7 & 47.2 & 5.5 \\
\hline $\begin{array}{l}\text { 9. Recognizes cause and } \\
\text { effect }\end{array}$ & 16.7 & 66.7 & 50 \\
\hline 10. Compares characters & 25.0 & 66.7 & 41.7 \\
\hline
\end{tabular}


Next, a paired samples $t$-test was conducted at a 95\% confidence interval using SPSS software to determine the statistical significance of the growth for each of the ten reading skills. As shown in Table 2, some of the reading skills of students increased to a higher degree than others and the effects of the treatment were significant. The paired tests of five Mastery Skills: (a) uses simple strategies, (b) determines the main idea, (c) recognizes persuasive text, (d) recognizes cause and effect, and (e) compares characters produced a two-tailed significant coefficient of .000 which suggested that it was likely that the tutorial software had a statistically significant effect on increasing these Mastery Skills. The paired tests of five Mastery Skills: (a) determines author's purpose, (b) reads and organizes information, (c) makes comparisons, (d) uses reference materials, and (e) understands plot produced a two-tailed significant coefficient greater than the .05 alpha level. Thus, the effect of the reading comprehension software program was determined not to be statistically significant on these Mastery Skills.

Table 2. Paired-Samples t-Tests of Significance Results $(\mathrm{N}=35)$

\begin{tabular}{|c|c|c|c|c|c|c|}
\hline Pair & $\begin{array}{c}M \\
\text { differe- } \\
\text { nce }\end{array}$ & $S D$ & $\begin{array}{c}S E \\
\text { mean }\end{array}$ & $\begin{array}{l}t \text {-test } \\
\text { value }\end{array}$ & & $\begin{array}{l}2- \\
\text { tailed } \\
\text { sig. }\end{array}$ \\
\hline $\begin{array}{l}\text { 1. Uses simple } \\
\text { strategies }\end{array}$ & +.500 & .663 & .114 & +4.398 & 34 & .000 \\
\hline $\begin{array}{l}\text { 2. Determines } \\
\text { the main idea }\end{array}$ & +.600 & .604 & .102 & +5.878 & 34 & .000 \\
\hline $\begin{array}{l}\text { 3. Determines } \\
\text { author's } \\
\text { purpose }\end{array}$ & +.057 & .236 & .404 & +1.435 & 34 & .160 \\
\hline $\begin{array}{l}\text { 4. Reads and } \\
\text { organizes } \\
\text { information }\end{array}$ & +.086 & .284 & .048 & +1.785 & 34 & .083 \\
\hline $\begin{array}{l}\text { 5. Recognizes } \\
\text { persuasive text }\end{array}$ & +.114 & .323 & .055 & +2.095 & 34 & .044 \\
\hline $\begin{array}{l}\text { 6. Makes } \\
\text { comparisons }\end{array}$ & +.086 & .284 & .048 & +1.785 & 34 & .083 \\
\hline $\begin{array}{l}\text { 7. Uses } \\
\text { reference } \\
\text { materials }\end{array}$ & +.057 & .236 & .404 & +1.435 & 34 & .160 \\
\hline $\begin{array}{l}\text { 8. Understands } \\
\text { plot }\end{array}$ & +.057 & .236 & .404 & +1.435 & 34 & .160 \\
\hline $\begin{array}{l}\text { 9. Recognizes } \\
\text { cause and effect }\end{array}$ & +.514 & .507 & .086 & -6.000 & 34 & .000 \\
\hline $\begin{array}{l}\text { 10. Compares } \\
\text { characters }\end{array}$ & +.429 & .502 & .085 & +5.050 & 34 & .000 \\
\hline
\end{tabular}

Research Question 2: Will increased performance with reading comprehension have a collateral effect on students scoring higher with math word problems?

To determine whether or not increased performance with reading comprehension had a collateral effect on students scoring higher with math word problems, it was appropriate to compare pre-and posttest scores of a district created progress monitor assessment. An item analysis and comparison was conducted by the school district to ensure that the test items on the progress monitor instrument were closely matched to summative state assessments that assess mathematical curriculum standards. The progress monitor assessment consisted of 44 multiple-choice and gridded-response items that related to benchmark standards of the state standards in mathematics. Sixty percent (21 out of 35) of students experienced gains in mathematics during the course of the reading comprehension software treatment. Students earned a mean score of 32 correct on the pre- and 33 correct on the posttest (out of 44 possible points) resulting in an increase of 1 point.

A paired-samples $t$-test at a $95 \%$ confidence interval was conducted to determine the statistical significance between the pre- and posttest scale score points of students. The test produced a two-tailed significant coefficient of .210 which proved that that the tutorial software did not have a statistically significant effect in students scoring higher with math word problems if they experienced increased performance with reading comprehension.

Research Question 3: Is it possible for reading comprehension skills to be transferred to other academic areas, specifically in mathematics?

A Pearson Product Moment Correlation Coefficient was computed using SPSS software to test for a correlation between increased math scores and reading comprehension scores. The test produced a negative correlation of .006 which indicated that there was little correlation between the effects of the reading comprehension software program on student achievement in mathematics. The negative relationship between increased math scores and reading comprehension scores indicated that as reading scores increase as a result of the computer software, it is unlikely that student achievement in mathematics would increase as well. According to the results of the Pearson Product Moment Correlation Coefficient calculated in this study, it was not possible for reading comprehension skills to be transferred to the mathematic content area. 


\section{DISCUSSIONS}

The main purpose of this study was to examine the effect of a reading comprehension software program on student achievement. The quantitative data produced within this study supported that the reading comprehension software program is an efficient instructional tool for increasing student achievement in reading (research question number one). However, data produced within this study did not conclusively support that the increase of reading comprehension skills had a collateral effect on students scoring higher with math word problems (research question number two). Furthermore, data produced within this study did not conclusively support that it might be possible for reading comprehension skills to be transferred to other academic areas, specifically in mathematics, as indicated in research question number three.

A reading comprehension software program was implemented based on research outlined in the literature and, therefore, similar achievement results we anticipated. The findings suggest that Computer Assisted Instruction (CAI) is an effective way of increasing student achievement. The implications of the findings of this study are discussed as a function of two major factors that could be critical to facilitating optimal conditions of this study. One factor is the use of computer assisted instruction that has research-based instructional design components. There are specific instructional design components of software that accelerate student learning. It is critical that educational leaders select software that has research-based instructional design components that demonstrate the importance of: (a) having learners exercise some level of control over the pace and sequence of their instruction, (b) guiding students towards making correct answers rather than simply requiring them to persist until they respond correctly, (c) including embedded cognitive strategies, and (d) the skills or concepts to be learned involve motion or action (Bialo and Sivin-Kachala, 1996). Therefore, educational leaders should select software that contains explicit instruction designed to provide remedial services that address the deficiency of the student.

Another factor that could be critical to facilitating optimal conditions of this study is providing supplemental instruction in mathematics that includes teacher modeling of the analysis and solution process for sample word problems. The four-step problem-solving process of Polya (1945) requires the prob- lem solver to (a) read the problem, (b) understand the problem, (c) solve the problem, and (d) look back. The reading comprehension software program targeted reading comprehension that could aid students in the initial problem-solving phases. During treatment in the study, students received schema strategy training in problem schemata (conceptual understanding) and problem solution (procedural understanding). The third phase of the four-step problem-solving process requires that students select and use appropriate strategies to respond to the problem. These strategies might be student created or introduced by the teacher. In either case, there are a myriad of strategies that students can rely on to solve problems (e.g. use trial and error; look for patterns; make a model; eliminate possibilities; use simpler numbers; make a table, chart, or diagram; draw a picture; work backward; and estimate). Supplemental, explicit instruction in mathematics that included teacher modeling of the analysis, and solution process for sample word problems would have been beneficial to students in the third phase of the problemsolving process. The study identified several reasons that the program was effective, one of which was that, rather than isolating computer skills from academic learning, educational leaders should integrate technology into the instructional program. By supplementing the intervention with instruction related to the third phase of the problem-solving process, the analysis and solution process for sample word problems, it appears that the intervention would have the potential to have a collateral effect on students scoring higher with math word problems.

\section{CONCLUSIONS}

Although the primary goal of this intervention was to examine the effect of a reading comprehension software program on student achievement, it was proposed that positive results might transfer to achievement in other academic areas, specifically in math. Critical reflection on the success and shortcoming of the intervention were explored and discussed in a manner conducive to providing insight to educational leaders who plan to implement tutorial software as a means for increasing student achievement. The findings of this study supports full-scale implementation of the intervention as an efficient instructional tool to increase student achievement in reading. Educational leaders should select software 
that contains explicit instruction designed to provide remedial services that address the deficiency of the student. The reading comprehension software was an effective instructional tool for increasing student achievement in reading, but was not as successful at increasing student achievement mathematics.

Reading comprehension programs could aid students in mathematics in the initial problem-solving phases when conceptual understanding and procedural understanding is required of students. However, supplemental, explicit instruction that included teacher modeling of the analysis, and solution process for sample word problems should be integrated. Therefore, it is the educational leader's responsibility to promote the success of all students by advocating, nurturing, and sustaining an instructional program that is conducive to student learning. This approach is facilitated by providing technologies that are used in teaching and learning and that curriculum decisions are partially based on research.

There are several limitations to this study. First, this research integrated a reading comprehension software program into a summer school traditional language arts program for a period of 5 weeks. The shortness of the intervention limited reliable results, and a longer exposure to the intervention might have yielded results that would have been considered more reliable. Additional factors to consider in future studies include the level of performance and effort placed into the delivery of instruction by different teachers. The instructional activities selected by each teacher may have hindered or accelerated student achievement during the duration of the study and limited the reliability of the results. Future research should examine whether readingcomprehension software programs can make significant contributions to student learning in mathematics, particularly in solving word problems. An attempt to account for the different results produced by varied instructional settings should be made by researchers. Also, it is essential to determine specific exposure guidelines and the most effective teacher instruction.

\section{ACKNOWLEDGMENTS}

The author would like to thank his colleague in the Center for Educational and Instructional Technology Research (a University of Phoenix School of Advanced Studies research center) Dr. Mansureh Kebritchi for valuable feedback and encouraging him expand research and literature. The author would like to thank his wife April for providing love and encouragement and son Paxton for being an inspiration to conduct research that has the potential to improve teaching and learning. Thanks are also due to the research participants-all students: thank you for your participation, for without it, this research would not have been possible.

\section{Conflict of interests}

The author declare no conflict of interest.

\section{REFERENCES}

Adams, T. L. (2003). Reading mathematics: More than words can say. Reading Teacher, 56(8) 786-795.

Bialo, E.R., \& Sivin-Kachala, J. (1996). The effectiveness of technology in schools: A summary of recent research. Washington, DC: Software Publishers Association.

Carnine, L., \& Carnine, D. (2004). The interaction of reading skills and science content knowledge when teaching struggling secondary students. Reading \& Writing Quarterly, 20(2), 203-218.

Crowe, L. K. (2005). Comparison of two oral reading feedback strategies in improving reading comprehension of school-age children with low reading ability. Remedial and Special Education, 26(1), 32-42.

Fuentes, P. (1998). Reading comprehension in mathematics. The Clearing House, 72(2), 81-88.

Graesser, A. C., Singer, M., \& Trabasso, T. (1994). Constructing inferences during narrative text comprehension. Psychological review, 101(3), 371.

Hyde, A. (2007). Mathematics and cognition. Educational Leadership, 65(3), 43-47.

Jitendra, A., DiPipi, C. M., \& Perron-Jones, N. (2002). An Exploratory Study of Schema-Based WordProblem-Solving Instruction for Middle School Students with Learning Disabilities An Emphasis on Conceptual and Procedural Understanding. The Journal of Special Education, 36(1), 23-38

Kulik, J. A. (1994). Meta-analytic studies of findings on computer-based instruction. Technology assessment in education and training, 1, 9-34.

Pany, D., \& McCoy, K. M. (1988). Effects of corrective feedback on word accuracy and reading comprehension of readers with learning disabilities. Journal of Learning Disabilities, 21(9), 546550 .

Polya, G. (1945). How to Solve It. Princeton University Press. Princeton, $N J$

Sasser, J. E. (1991). The effect of using computer tutorials as homework assignments on the mathematics achievement of elementary education majors. Journal of Computers in Mathematics and Science Teaching, 10(2), 95-102.

Shany, M. T., \& Biemiller, A. (1995). Assisted reading practice: Effects on performance for poor readers in grades 3 and 4. Reading research quarterly, 382-395.

Steele, M. M., \& Steele, J. W. (1999). DISCOVER: An 
intelligent tutoring system for teaching students with learning difficulties to solve word problems. Journal of Computers in Mathematics and Science Teaching, 18(4), 351-359.

Vygotsky, L. S. (1978). Mind in society: The development of higher psychological processes. Cambridge, MA: Harvard University Press.

Vygotsky, L. S. (1987). Thinking and speech. In R.W. Rieber \& A.S. Carton (Eds.), The collected works of L.S. Vygotsky, Volume 1: Problems of general psychology (pp. 39-285). New York: Plenum Press. (Original work published 1934.)

Watson, J. (2001). How to Determine a Sample Size: Tipsheet\# 60, University Park, PA: Penn State Cooperative Extension. Retrieved on, 21(10), 2012. Retrieved from http://www.extension.psu. edu/evaluation/pdf/TS60.pdf

Winsler, A., Abar, B., Feder, M. A., Schunn, C. D., \& Rubio, D. A. (2007). Private speech and executive functioning among high-functioning children with autistic spectrum disorders. Journal of Autism and Developmental Disorders, 37(9), 1617-1635. 